\title{
From Stand Alone Computers to Big Data Technology: Proposing a New Model for Information Technology Infrastructure Change Management
}

\author{
Foluso Ayeni ${ }^{1 *}$, Stephen Adubi ${ }^{2}$, Olaperi Sowunmi ${ }^{3}$ and Victor Mbarika ${ }^{4}$ \\ ${ }^{1,4} \mathrm{~A} \&$ M College, International Center for Information Technology and Development Southern University, USA \\ ${ }^{2,3}$ Department of Computer and Information Sciences Covenant University, Nigeria
}

*Corresponding author: Foluso Ayeni, International Center for Information Technology and Development Southern University and A \& M College, Baton Rouge Lousisiana, USA

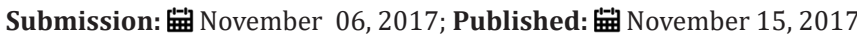

\begin{abstract}
Change is said to be constant but despite the benefits of change to Information Technology Infrastructure (ITI), managers, researchers and enthusiasts are uncertain about the future. A survey of literature shows that the association between ITI and change management are divergent in interrelationships. Many ITI consumers find it difficult to accommodate change due to several challenges involved. Technological developments coming into play has led to whole lot gradual changes. This paper describes the journey of ITI from standalone computers to cloud of things, the motivation for their transition alongside merits and demerits. It also discusses each of this method in brief and also provides their applications. It states the importance of computer networks today using fast and novel approaches. Finally, this paper presents a new model for managing change in ITI.
\end{abstract}

Keywords: Change; Information technology infrastructure; Computer networks

\section{Introduction}

Successful change management is key to achieving organizational success because of the ever changing and highly competitive, on-demand business environment. Information Technology Infrastructure (ITI) encompasses all components involved in Information technology operations. It can be used for business solutions, customer relations or internal business operations. Change Management can be defined as a continuous process of redefining the structure, ability and direction of an organization towards attaining maximum client satisfaction [1]. Changes in ITI requirements are an inevitable process [2]. From the era of standalone computers to big data technology and cloud of things, infrastructure has always been a resource sharing of information technology through the communication between people and technology in industries and organizations [3]. Popoola M [4] also described ITI as a framework that involves technological tools used for exchanging and managing knowledge in modern information flow. This flow exists in software, hardware and telecommunication. ITI change has contributed positively and negatively to organizational performance. A trace of the historical linkage from computer networks to big data technology shows that there are more ITI technologies yet to come in the nearest future (Figure 1). Complexity involved in accommodating ITI change in organizations is alarming and managers find it difficult due to its effect on Return on Investment (ROI).

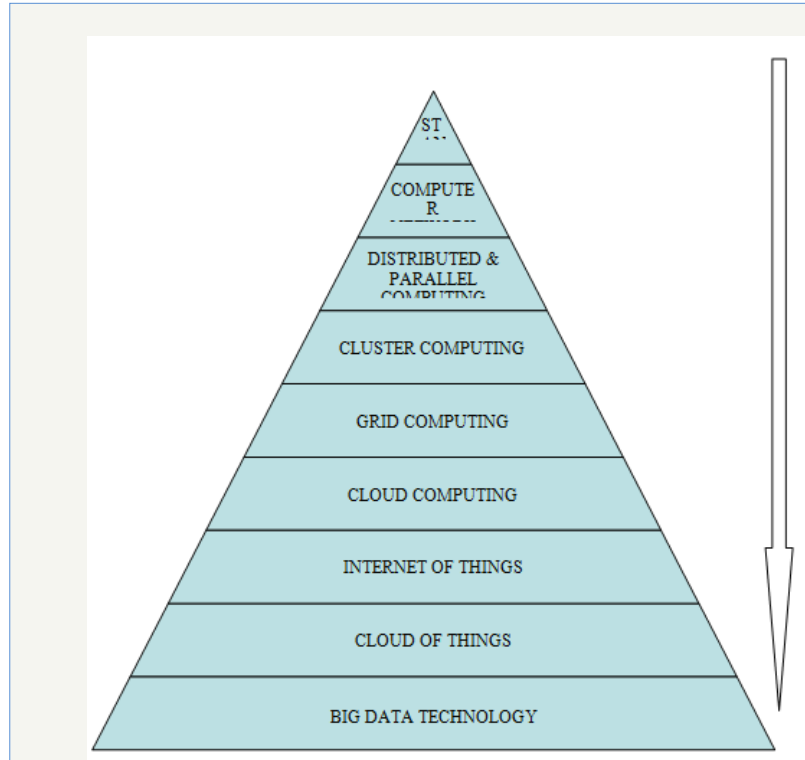

Figure 1: Evolution of trends from stand alone computers to Big Data Technology.

This work is proposed to present and describe the journey from standalone computers to Big Data Technology and also present a new model for ITI change management. 


\section{Statement of Problem and Objective of Study}

At the onset of computing, computers were majorly standalone systems, i.e. independent, and without any form of communication to other computing systems. These systems were usually very large and for general purposes, however, gradually different technological developments came into play causing gradual changes, one after the other and now, we are close to having almost the opposite of what was the norm at the beginning, wherein everything can actually be connected, and one to another. Different problems have led to different computing paradigms, in a bid to proffer more effective and efficient solutions.

\section{Review of Trends/Technologies}

ITI depicts the information technology resources that leverage business applications. Sequel to the 1980s, the advantages of Information technology (IT) became numerous such as helping firms raise entry barriers, offer new products and services and increasing bargaining potentials with suppliers and customers [5]. From computer networks to distributed computing which progressed gradually to cluster and grid computing and their different variations. The concept of utility computing then led to cloud computing while device miniaturization and the advancement of the internet and wireless networks brought about the internet of things. The amalgamation of cloud computing and internet of things has resulted in the cloud of things. The effect of all these paradigms is massive data being generated and transferred spontaneously giving birth to Big Data as we have it today.

\section{Stand alone computers}

A standalone computer is one that is connected to another computer or network such as hubs, switches or routers, Local Area Network or Internet (NCB, 2011). These systems run strictly in operating systems such as Windows, Linux and Mac. Securing data on standalone computers lies solely on its physical security and access controls. Standalone computers came into existence in the early 1980 s.

\section{Computer networks}

This is the connection of computers (forming nodes) over a geographical location with the provision to share resources governed by a set of rules (called protocols). The network models are Local Area Network (LAN), Metropolitan Area Network (MAN) and the Wide Area Network (WAN) also called the Internet. The computer network formed the basis for the forms of distributed computing from Cluster Computing to Internet of Things (IoT).

\section{Distributed and parallel computing}

It is a type of computing in which different components and objects of an application/software system are located on different computers connected to a network, in a bid to solve a problem that cannot be completely executed in an acceptable specified time on a single computer. This aims to improve the efficiency and performance of large programs because the program is run simultaneously on different systems [6]. In parallel computing, applications are executed concurrently and the main focus is highperformance computing.

\section{Cluster computing}

Cluster computing was inspired by a need to provide a more cost effective form of parallelism as opposed to linking large mainframe computers together. This was in the 1960s; however it was during the 1980s that it gained momentum due to 3 trends namely [7]: high performance microprocessors, standard tools for high performance distributed computing and high speed networks. The relative low cost and availability of these technologies really encouraged this paradigm.

\section{Grid computing}

Finn W [8] defines it as a "data management and computing infrastructure" that integrates four concepts, information, computation, networking and communication providing a platform for linking resources dynamically. These resources are then used to support application execution requiring large amount of resources at once. The nodes in a grid can be personal computers (PCs), clusters, laptops or PDAs and they are connected via a network (WAN or the Internet) [9]. The basic concept of grid computing stems from power grids where users have access to electricity through sockets and wired connections with little or no knowledge where the electrical power comes from [10].

\section{Cloud computing}

Utility computing coupled with the concept of grid computing has brought about cloud computing. It is defined as: "a model for enabling ubiquitous, convenient, on-demand network access to a shared pool of configurable computing resources (e.g., networks, servers, storage, applications, and services) that can be rapidly provisioned and released with minimal management effort or service provider interaction [11]. The availability of high speed internet today, coupled with concepts like the service oriented architecture (SOA), multi-tenancy and virtualization have facilitated its success. In addition to the NIST definition, other authors and stakeholders have given their own definitions of the newly emerging [12] and evolving paradigm [6]. Kahanwal D [9] defined the concept as the use of computer resources not internally owned with the benefits of scalability, low operational cost and on-demand provisioning. It can be defined as a shared network of machines enabling individuals and organizations to store data and run software [13]. Finally [6] defined cloud computing as a parallel and distributed system housing a shared pool of virtual resources in big resource point.

\section{Internet of things}

In 2009, a dedicated European Union (EU) commission action plan defined IoT from their perspective: seeing it as the evolution from the network of computers to the network of interconnected objects. From the perspective of [12], Cloud computing is the underlying framework for the activities of the IoT technology since communication among devices need a form of central data access 
points where details about each device (living or non-living) will be stored for 'ubiquitous' access.

\section{Cloud of things}

Cloud of things (COT) is a concept that merges the characteristics of IOT and cloud computing. Cloud of things enables businesses to develop branded internet of things solutions easily and quickly.

Big Data Technology: Big Data Technology (BDT) is one the latest technology-enabled business developments that has reformed strategy across an extensive range of organizations [14]. It also leverage on cloud computing paradigm by providing Data-asa-Service. In [15], BDT was defined as a new technology generation technique developed to enable institutions and organizations extract value economically from huge volumes and variety of data via discovery, analysis and velocity capture.

\section{Framework of ITI Historical Linkage}

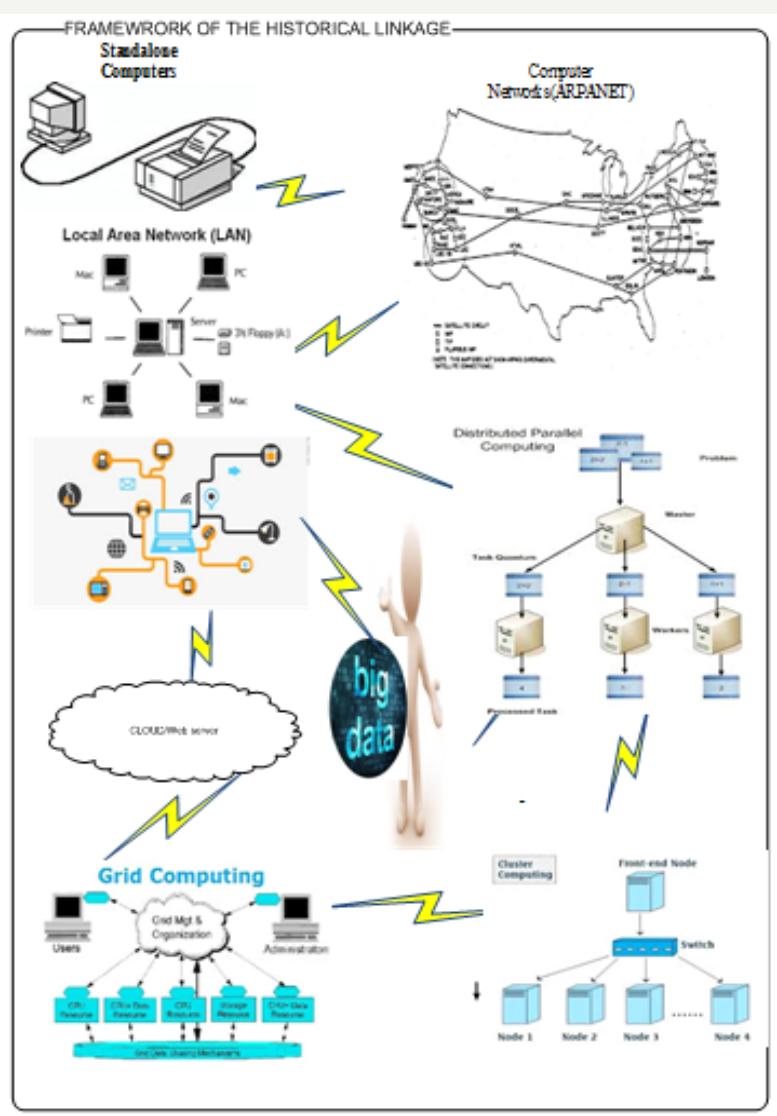

Figure 2: Framework of the historical linkage.

Figure 2 depicts the framework of historical linkage discussed so far. The advent of computer networks and the internet spurred previously unimaginable technologies. Current research areas include the internet of things, cloud of things and big data. All 'things' in the world would soon be connected and leveraging on processed data, 'things' would be able to make intelligent decisions and assist humans to do the same without any human intervention. The best is still to come.

\section{Proposed Model}

It is expedient to note that change has been the underlying force behind the current unceasingly and evolving business environment. Therefore, successful change management is a required skill [16]. Managing organizational change is a reactive and discontinuous process. Lack of a valid framework to implement and manage organizational change has led to loss in ROI for most organizations. This section proposes a new model for managing ITI based organizational change. Figure 3 shows the injection of change component and how it evolves round ITI and Business Continuity Plan (BCP). Every time there is a change in ITI trend, BCP tend to accommodate this change automatically which will therefore reduce cost incurred by organizations.

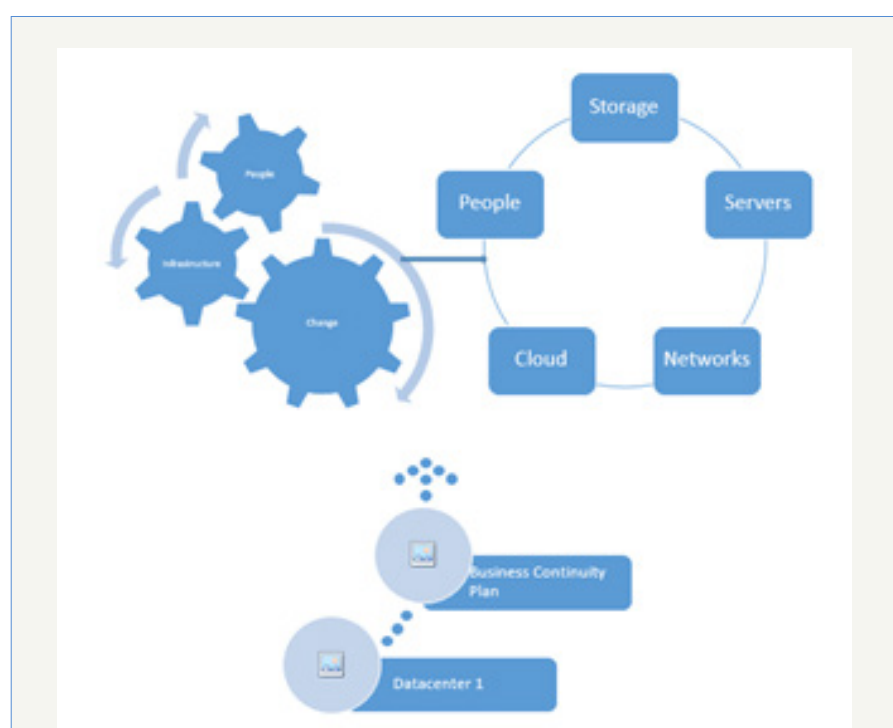

Figure 3: Proposed ITI change management model.

\section{Conclusion and Future Work}

This study has strengthened and explored the need to better improve and manage change in ITI. The study also showed a brief review of ITI historical trends. The adoption of the model will definitely improve ITI management and boost ROIs in organizations. Future work will therefore drive towards the introduction of an expanded re-engineered framework and also present an implementation plan using a reputable organization as a test base.

\section{Acknowledgment}

The support of 0. Daramola and other Faculty members in the Department of Computer and Information sciences, Covenant University, are gratefully acknowledged for access to information and guidance towards success of the work.

\section{References}

1. Todnem BR (2005) Organizational change management: A critical review. Journal of Change Management 5(4): 369-380.

2. Chaturvedi A (2014) Automated web service change management awscm-a tool. Cloud computing technology and science (Cloud Com), IEEE $6^{\text {th }}$ International Conference, IEEE, Singapore. 
3. Gheysari H, Amran R, Parastoo R, Hamid J (2012) The role of information technology infrastructure capability (ITIC) in management. IJFPSS 2(2): 36-40.

4. Popoola M (2002) Integration, en samtidsspegling: en översikt. Svenska kommunförbundet, p. 77.

5. Bhatt GD, Emdad AF (2010) An empirical examination of the relationship between information technology (IT) infrastructure, customer focus, and business advantages. Journal of Systems and Information Technology 12(1): 4-16.

6. Hajibaba M, Gorgin S (2014) A review on modern distributed computing paradigms: Cloud computing, jungle computing and fog computing. Journal of Computing and Information Technology 22(2): 69-84.

7. Yeo CS, Rajkumar B, Hossein P, Rasit E, Peter G, et al. (2006) Cluster computing: high-performance, high-availability, and high-throughput processing on a network of computers, in Handbook of nature-inspired and innovative computing. Springer, p. 521-551.

8. Finn W (2011) Grid Computing - Definition and Disadvantages, bright hub.
9. Kahanwal B, Singh TP (2013) The distributed computing paradigms: P2P, grid, cluster, cloud, and jungle. International Journal of Latest Research in Science and Technology 1(2): 183-187.

10. Jacob B, Brown M, Fukul K, Trivedi N (2005) Introduction to Grid Computing $\left(1^{\text {st }} \mathrm{edn}\right)$, International Technical Support Organization.

11. Mell P, Grance T (2011) The NIST definition of cloud computing. NLST.

12. Gubbi J, Rajkumar B, Slaven M, Marimuthu P (2013) Internet of Things (IoT): A vision, architectural elements, and future directions. Future Generation Computer Systems 29(7): 1645-1660.

13. http://www.datahouse.com/assets/files/Cloud-1.0.pdf

14. Bughin J, Chui M, Manyika J (2010) Clouds, big data, and smart assets: Ten tech-enabled business trends to watch. McKinsey Quarterly 56(1): 75-86.

15. Villars RL, Olofson CW, Eastwood M (2011) Big data: What it is and why you should care. White Paper, IDC, Framingham, Massachusetts, USA.

16. Balogun J (2004) Veronica Hope Hailey Exploring Strategic Change, $\left(2^{\text {nd }}\right.$ edn), Financial time. Prentice hall, New Jersey, USA. 